\title{
SISTEM INFORMASI PELANGGAN DI RUMAH MAKAN NASIONAL
}

\author{
Thomas Priyasmanu ${ }^{1}$, Anang Subardi ${ }^{2}$ \\ ${ }^{1)}$ Teknik Industri, Institut Teknologi Nasional Malang \\ ${ }^{2)}$ Teknik Mesin, Institut Teknologi Nasional Malang \\ thomas_itn@yahoo.co.id
}

\begin{abstract}
ABSTRAK
Rumah makan merupakan tempat singgah yang sering menjadi tujuan dari banyak orang terutama pada jam makan, oleh kerena itu pada saat jam makan baik itu makan siang dan makan malam biasanya rumah makan dipenuhi pelanggan, sehingga pelayanan menjadi kurang maksimal disebabkan banyaknya pelanggan, salah satu solusi yang bisa ditawarkan adalah pembuatan sistem informasi rumah makan, sehingga pada saat rumah makan ramai, pelayanan pemesanan dan pembayaran dapat dilakukan dengan cepat dan akurat, pada penelitian ini dibuat suatu sistem informasi rumah makan nasional dengan tujuan untuk meningkatkan tingkat kepuasan pelanggan karena peningkatan waktu pelayanan terutama pada saat pemesanan dan pembayaran di kasir.
\end{abstract}

Keyword : Sistem Informasi, Rumah makan

\section{PENDAhuluan}

Warung nasional dua merupakan salah satu rumah makan yang cukup diminati pelanggan karena memiliki harga yang realatif murah dengan makanan khas Jawa dengan cita rasa yang enak, sehingga pada jam makan terutama siang dan malam rumah makan ini sangat dipenuhi oleh pelanggan, sehingga pelayanan menjadi sedikit terganggu karena proses pemesanan dan pembayaran di kasir dilakukan secara manual sehingga membutuhkan waktu untuk menghitung total pengeluaran pelanggan, hal ini dapat menyebabkan pelanggan menjadi kurang nyaman karena pelayanan yang kurang cepat.

Salah satu alternatif yang dapat ditawarkan adalah pembuatan sistem informasi rumah makan, sehingga proses pemesanan dan pembayaran di kasir dapat dilakukan secara otomatis dan dapat dilakukan dengan cepat, dengan pembuatan sistem infomasi ini pelanggan akan semakin senang karena tidak terjadi antrian pada saat pemesanan dan pembayaran, sehingga jika banyak pelanggan yang merasa senang tingkat pendapatan rumah makan akan semakin meningkat.

\section{TINJAUAN PUSTAKA}

\section{Pengertian Sistem Informasi dan Teknologi Informasi}

Menurut O'Brien (2007, P45), sistem informasi adalah gabungan yang terorganisasi dari manusia, perangkat lunak, perangkat keras, jaringan komunikasi, dan sumber daya data dalam mengumpulkan, mengubah dan menyebarkan informasi dalam organisasi.

Sedangkan teknologi informasi adalah teknologi pendukung dari sistem informasi yaitu sistem berbasis Teknologi Informasi (TI) yang mengelola komponen-komponennya berupa hardware, software, netware, dataware, dan brainware untuk melakukan transformasi data menjadi informasi.

\section{Tujuan Pengembangan Sistem Informasi}

Setiawan (2013: 9) mengungkapkan ada 5 (lima) tujuan dari pengembangan sistem informasi yaitu, diantaranya:

a. Agar organisasi dapat beroperasi secara efisien

SIM mengerjakaan pekerjaan-pekerjaan rutin secara lebih cepat dan mudah. (Transaction Processing System), contoh sistem penerimaan gaji, sistem akuntansi, sistem personalia, sistem persediaan dan sebagainya.

b. Agar organisasi dapat beroperasi secara efektif

Efektifitas ini dimaksudkan agar dapat mencapai target dari sistem pendukung keputusan (Decision Support System / DSS). DSS memberikan informasi khusus kepada para pembuat keputusan dengan informasi dan model-model tersebut dapat ditampilkan setiap kali dibutuhkan, sehingga para manajer dapat mengambil keputusan dengan lebih baik.

c. Agar organisasi dapat memberikan pelayanan yang lebih baik

Dengan sistem informasi manajemen maka kebutuhan terhadap informasi dapat segera dipenuhi dengan mudah yang pada akhirnya akan mampu meningkatkan kualitas pelayanan kepada konsumen. Contoh : penggunaan perangkat sistemAutomatic Teller Machine (ATM) pada Bank.

d. Agar Organisasi dapat meningkatkan kreasi / improvisasi terhadap produk yang dihasilkan

Hal ini sangant dimungkinkan karena SIM akan mengintegrasikan informasi-informasi dalam organisasi sehingga dapat membantu pengembangan usahanya melalui kreasi-kreasi produk baik barang maupun jasa. Contoh : suatu Bank yang melebarkan usahanya dalam bidang pelayanan jasa asuransi, pelayanan pembayaran rekening telepon, listrik dan sebagainya. 
e. Agar organisasi dapat meningkatkan usaha

SIM yang baik akan meningkatkan pangsa pasar terhadap produk yang dihasilkannya. SIM akan dapat mengakibatkan terjadinya ketergantungan konsumen terhadap pelayanan yang diberikan organisasi tertentu sehingga konsumen merasa enggan untuk berpindah pada organisasi atau perusahaan lain.

\section{Tujuan Teknologi Informasi}

Adapun tujuan dari teknologi informasi yaitu, diantaranya:

a. Memecahkan suatu permasalahan;

b. Membuka kreativitas, efektivitas, efisiensi;

c. Memotivasi kemampuan seseorang agar bisa beradaptasi dan mengantisipasi perkembangan Teknologi Informasi;

d. Mengembangkan kompetensi.

\section{Manfaat Sistem Informasi}

Setiawan (2013 : 33) menyatakan ada 4 (empat) manfaat dari sistem informasi yaitu diantaranya:

1. Merampingkan organisasi dan mengubah proses manajemen;

2. Memisahkan kerja dari lokasi;

3. Mengatur ulang alur kerja;

4. Meningkatkan fleksibilitas organisasi.

\section{Manfaat Teknologi Informasi}

Menurut Jogiyanto (2003: 18) terdapat 5 (lima) manfaat dari adanya teknologi informasi yaitu diantaranya :

1. Meningkatkan efisiensi yaitu menggantikan manusia dengan teknologi dalam proses produksi.

2. Meningkatkan efektivitas yaitu menyediakan informasi bagi para manajer dalam organisasi untuk mendukung proses pengambilan keputusan dengan lebih efektif yang didasarkan dengan informasi yang akurat, tepat waktu, dan relevan sehingga mendapatkan hasil produksi yang akurat dan bebas dari cacat produksi sesuai dengan sasaran produksi yang diinginkan.

3. Meningkatkan komunikasi yaitu mengintegrasikan penggunaan SIM dengan menggunakan $e$-mail dan chat.

4. Meningkatkan kolaborasi yaitu dengan menggunakan video conference dan teleconference.

5. Meningkatkan kompetetif yaitu teknologi informasi digunakan untuk keunggulan kompetisi.

\section{Jenis - Jenis Sistem Informasi}

Menurut O'Brien (2007) secara garis besar sistem informasi dikelompokkan manjadi dua jenis, yaitu :

\section{Sistem Pendukung Operasional}

Jenis sistem ini terkait dengan operasional sehari-hari yang berlangsung di dalam suatu organisasi:

a. Sistem pemrosesan transaksi, sistem ini memproses data hasil transaksi bisnis, memperbaharui basis data operasional, menghasilkan dokumen bisnis. Contoh : pemrosesan penjualan dan persediaan serta sistem akuntansi.

b. Sistem pengendalian proses, sistem ini terkait dengan proses mengawasi dan mengendalikan proses industry. Contoh : sistem produksi baja, penyulingan minyak dengan sensor yang terhubung komputer.

c. Sistem kerjasama antar tim atau bagian perusahaan, sistem ini terkait dengan dukungan komunikasi dan kerjasama tim atau bagian atau kelompok kerja disuatu organisasi atau perusahaan dengan memanfaatkan piranti elektronik dan teknologinya. Contoh : e- mail, fax, teleconference.

\section{Sistem Pendukung Manajemen}

a. Sistem Informasi Manajemen

Sistem ini memberikan informasi laporan yang sudah ditentukan sebelumnya untuk mendukung pengambilan keputusan bisnis. Contoh : analisis penjualan, kinerja produksi, dan sistem pelaporan tren biaya.

b. Sistem Pendukung Keputusan

Sistem ini memberikan dukungan interaktif khusus untuk proses pengambilan keputusan para manajer dan praktisi bisnis. Contoh : penetapan harga produk, perkiraan tingkat laba, sistem analisis resiko.

c. Sistem Informasi Eksekutif

Sistem ini dibentuk untuk memenuhi kebutuhan eksekutif yang diperoleh dari SIM maupun Sistem Pendukung Keputusan (Decision support System). Contoh : sistek akses yang mudah untuk menganalisis kinerja bisnis, tindakan para pesaing, perkembangan ekonomi untuk mendukung perencanaan strategis.

\section{DFD Level 1}

DFD Level 1 merupakan perspesifikasian proses dari level 0, dalam level ini proses akan dipecah menjadi 3 proses, antara lain proses pendataan menu, proses transaksi penjualan, dan proses pembuatan laporan. 


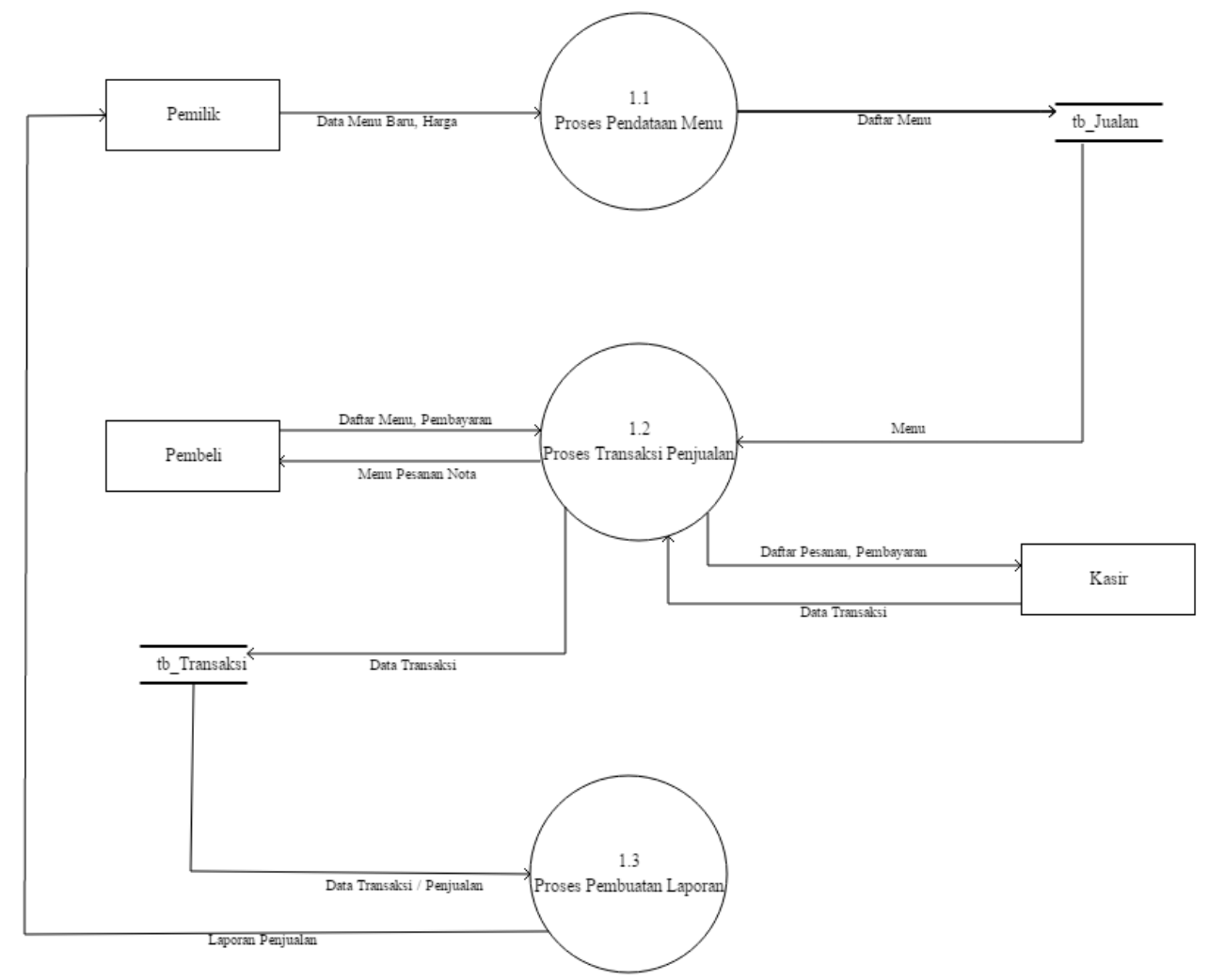

Gambar 1. DFD Level 1

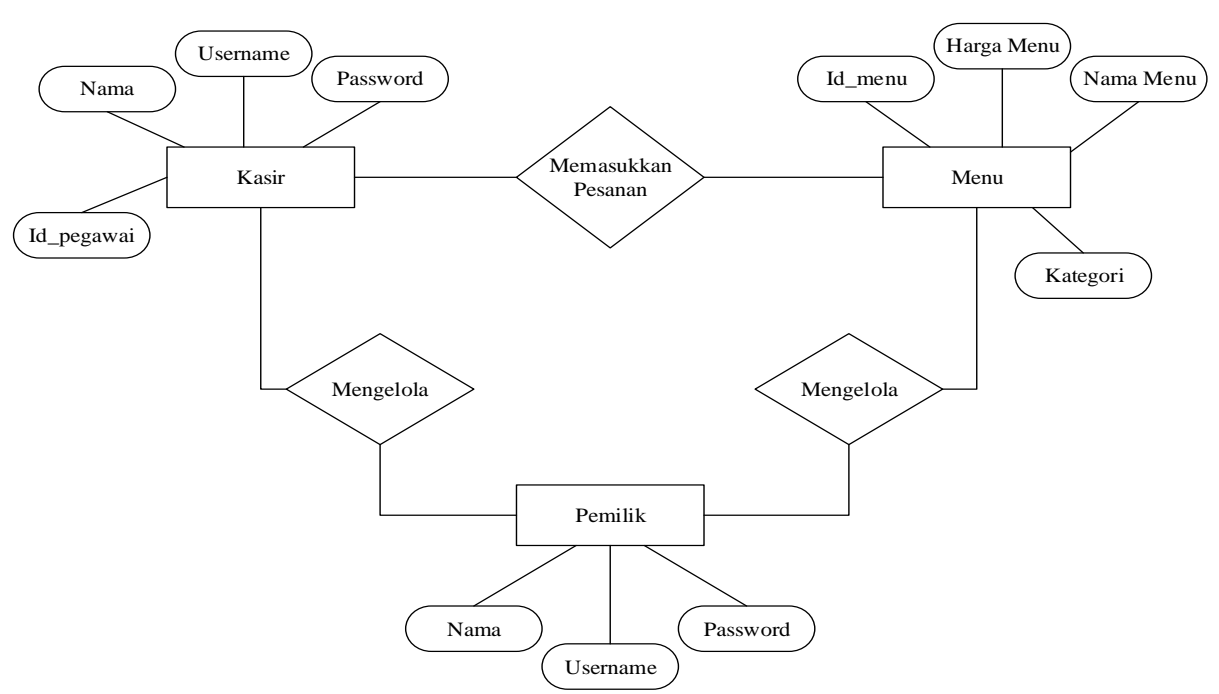

Gambar 2. Entity Relationship Diagram 


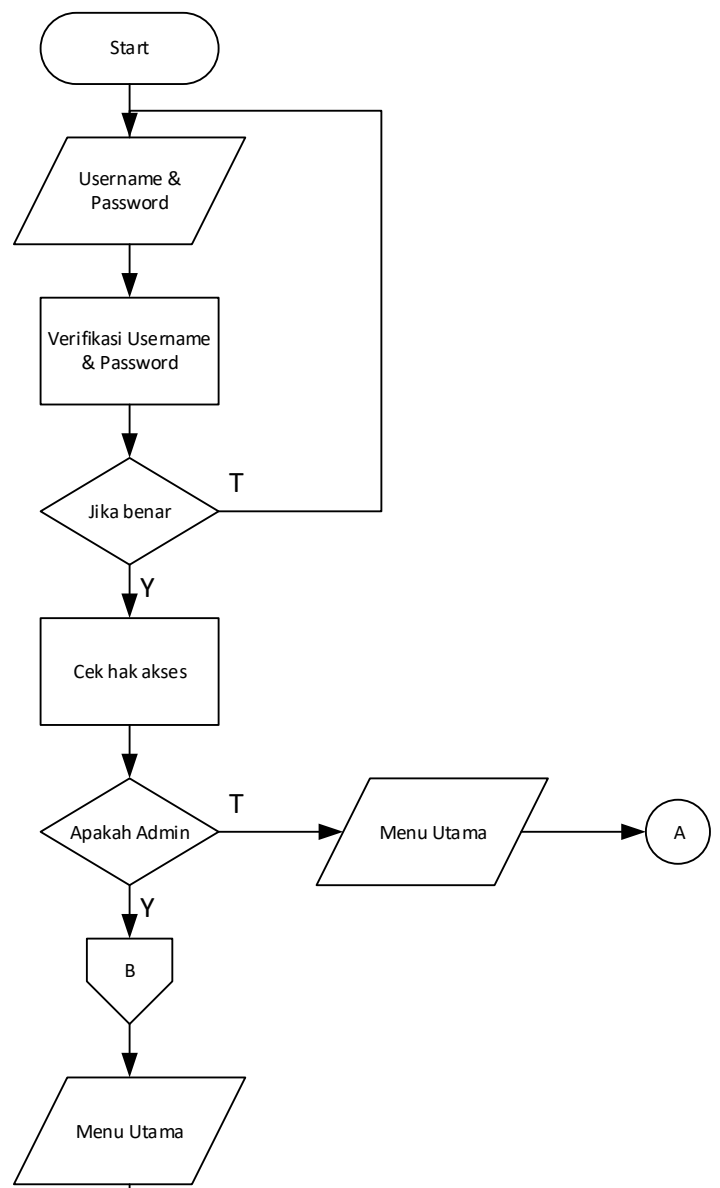

yang berbeda box biasanya digunakan untuk entitas, diamond digunakan untuk penghubung dan oval di gunakan untuk mewakili atribut, dan ERD dari aplikasi pembagian honor ini adalah :

\section{Flowchart}

System flowchart dapat didefinisikan sebagai bagan yang menunjukkan arus pekerjaan secara keseluruhan dari sistem. Bagan ini menjelaskan urut-urutan dari prosedur - prosedur yang ada di dalam sistem. Bagan alir sistem menunjukkan apa yang dikerjakan di sistem. Berikut ini adalah flowchart dari aplikasi kasir rumah makan nasional 2:

\section{Keterangan :}

Dimulai dari menu login kemudian memasukan username dan password, kemudian dilakukan verifikasi apabila username dan password salah, akan diminta untuk memasukkan username dan password ulang, dan jika username dan password benar, maka akan dilakukan pengecekan hak akses. Jika admin akan masuk ke menu utama yang didalam nya terdapat menu admin, menu transaksi, menu katering, dan menu laporan. Sedangkan jika kasir, akan masuk ke menu utama yang hanya terdapat menu katering dan menu transaksi.

Di menu admin terdapat fungsi tambah menu, edit menu, hapus menu. Pada fungsi tambah menu, akan ditampilkan list menu yang sudah ada sebelumnya, kemudian masukkan data menu baru, dan simpan data yang telah dimasukkan tadi. Pada fungsi edit menu, data menu juga akan ditampilkan dalam list menu, kemudian pilih salah satu dari daftar menu yang ada untuk di edit datanya, setelah itu masukkan data menu baru dan simpan data yang telah dirubah tadi. Pada fungsi hapus menu, list menu yang sudah akan ditampilkan, kemudian pilih menu yang ingin dihapus, kemudian pilih hapus menu dan kemudian kembali ke menu utama.

Di dalam menu laporan, terdapat fungsi laporan untuk mencetak laporan penjualan. Di dalam menu transaksi, terdapat submenu pesanan baru, pesanan belum selesai, pesanan selesai. Pada submenu pesanan baru, kemudian masukkan data pesanan baru, kemudian simpan data pesanan baru tersebut. Pada submenu pesanan belum selesai, akan ditampilkan list pesanan yang belum selesai, kemudian pilih salah satu dari daftar pesanan yang ada, pilih apakah update pesanan atau hapus pesanan, jika update pesanan, masukkan data pesanan yang baru kemudian simpan, dan apabila ingin menghapus pesanan, maka hapus pesanan yang sudah dipilih.

Pada menu pesanan selesai, terdapat daftar transaksi yang sudah selesai di bayarkan. Pada menu katering terdapat submenu pesanan baru, pesanan belum lunas, dan pesanan selesai. Jika pesanan baru, masukkan data pesanan baru kemudian simpan data 
pesanan yang sudah di masukkan sebelumnya. Jika pesanan belum lunas, akan ditampilkan daftar pesanan yang belum selesai dibayarkan, kemudian pilih salah satu dari daftar pesanan, jika ingin merubah status pembayaran, masukkan nominal uang yang dibayarkan, kemudian hitung nominal pembayaran, kemudian ubah status pembayaran. Apabila ingin menghapus pesanan, hapus pesanan yang sudah dipilih sebelumnya. Di dalam submenu pesanan selesai, akan ditampilkan daftar transaksi atau pesanan yang sudah dibayarkan pembayarannya.

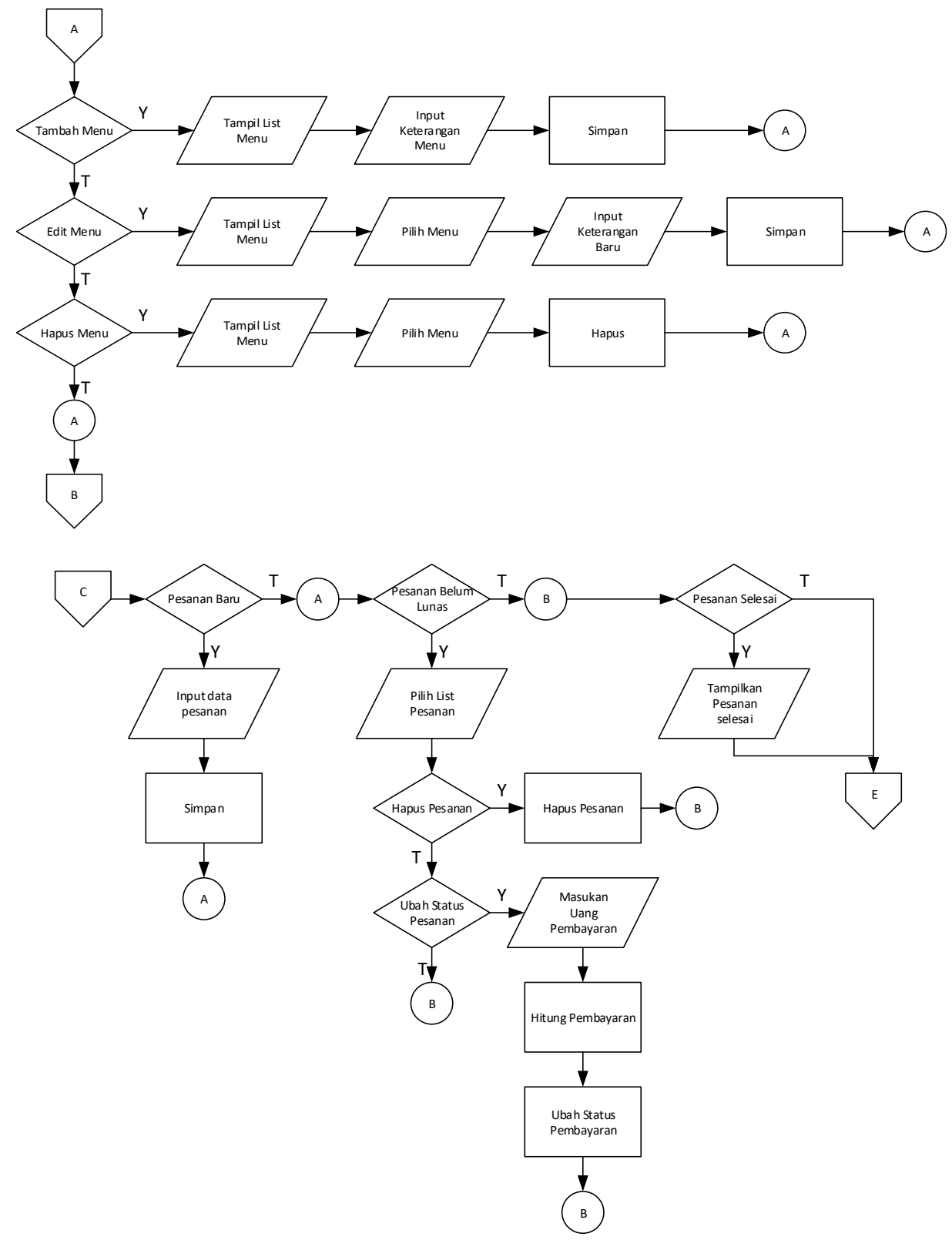




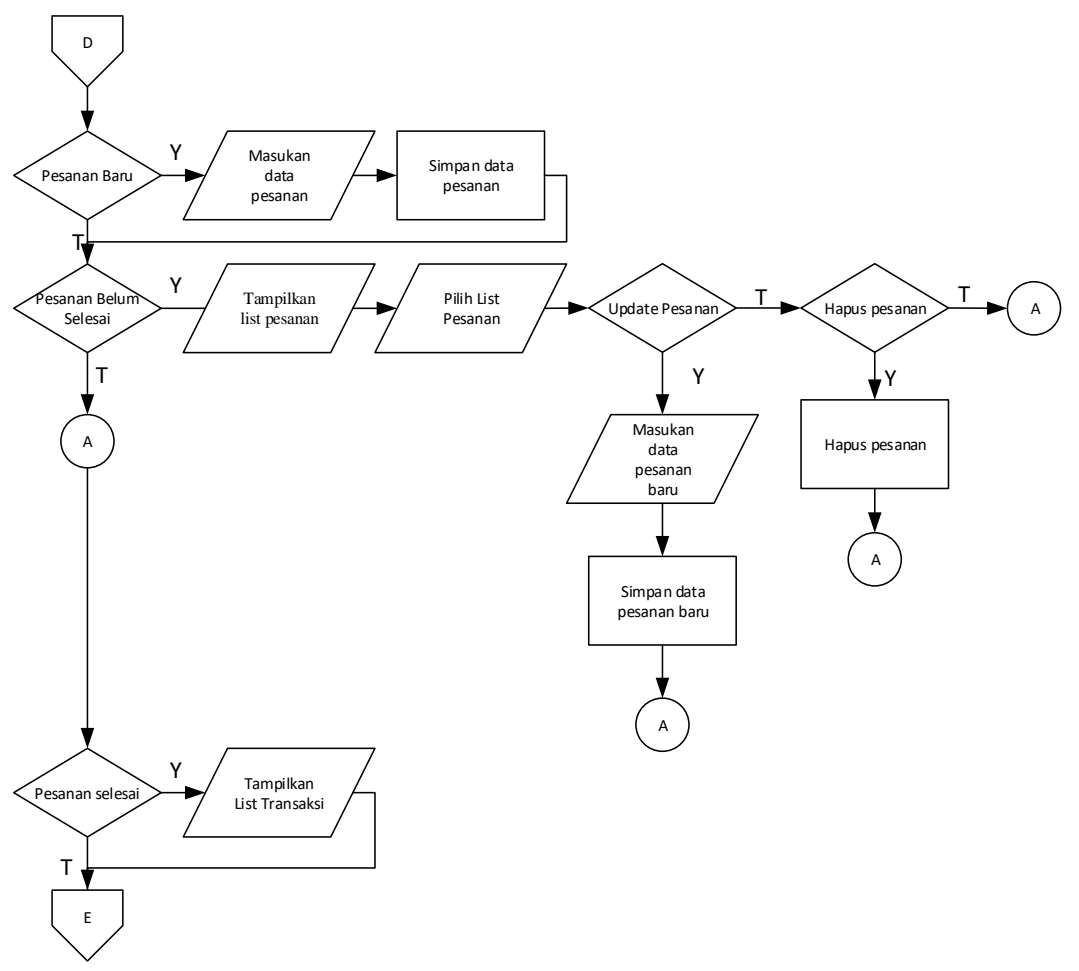

Gambar 3. Flowchart Aplikasi rumah makan nasional 2

\section{Keterangan :}

Dimulai dari menu login kemudian memasukan username dan password, kemudian dilakukan verifikasi apabila username dan password salah, akan diminta untuk memasukkan username dan password ulang, dan jika username dan password benar, maka akan dilakukan pengecekan hak akses. Jika admin akan masuk ke menu utama yang didalam nya terdapat menu admin, menu transaksi, menu katering, dan menu laporan. Sedangkan jika kasir, akan masuk ke menu utama yang hanya terdapat menu katering dan menu transaksi.

Di menu admin terdapat fungsi tambah menu, edit menu, hapus menu. Pada fungsi tambah menu, akan ditampilkan list menu yang sudah ada sebelumnya, kemudian masukkan data menu baru, dan simpan data yang telah dimasukkan tadi. Pada fungsi edit menu, data menu juga akan ditampilkan dalam list menu, kemudian pilih salah satu dari daftar menu yang ada untuk di edit datanya, setelah itu masukkan data menu baru dan simpan data yang telah dirubah tadi. Pada fungsi hapus menu, list menu yang sudah akan ditampilkan, kemudian pilih menu yang ingin dihapus, kemudian pilih hapus menu dan kemudian kembali ke menu utama.

Di dalam menu laporan, terdapat fungsi laporan untuk mencetak laporan penjualan. Di dalam menu transaksi, terdapat submenu pesanan baru, pesanan belum selesai, pesanan selesai. Pada submenu pesanan baru, kemudian masukkan data pesanan baru, kemudian simpan data pesanan baru tersebut. Pada submenu pesanan belum selesai, akan ditampilkan list pesanan yang belum selesai, kemudian pilih salah satu dari daftar pesanan yang ada, pilih apakah update pesanan atau hapus pesanan, jika update pesanan, masukkan data pesanan yang baru kemudian simpan, dan apabila ingin menghapus pesanan, maka hapus pesanan yang sudah dipilih.

Pada menu pesanan selesai, terdapat daftar transaksi yang sudah selesai di bayarkan. Pada menu katering terdapat submenu pesanan baru, pesanan belum lunas, dan pesanan selesai. Jika pesanan baru, masukkan data pesanan baru kemudian simpan data pesanan yang sudah di masukkan sebelumnya. Jika pesanan belum lunas, akan ditampilkan daftar pesanan yang belum selesai dibayarkan, kemudian pilih salah satu dari daftar pesanan, jika ingin merubah status pembayaran, masukkan nominal uang yang dibayarkan, kemudian hitung nominal pembayaran, kemudian ubah status pembayaran. Apabila ingin menghapus pesanan, hapus pesanan yang sudah dipilih sebelumnya. Di dalam submenu pesanan selesai, akan ditampilkan daftar transaksi atau pesanan yang sudah dibayarkan pembayarannya. 


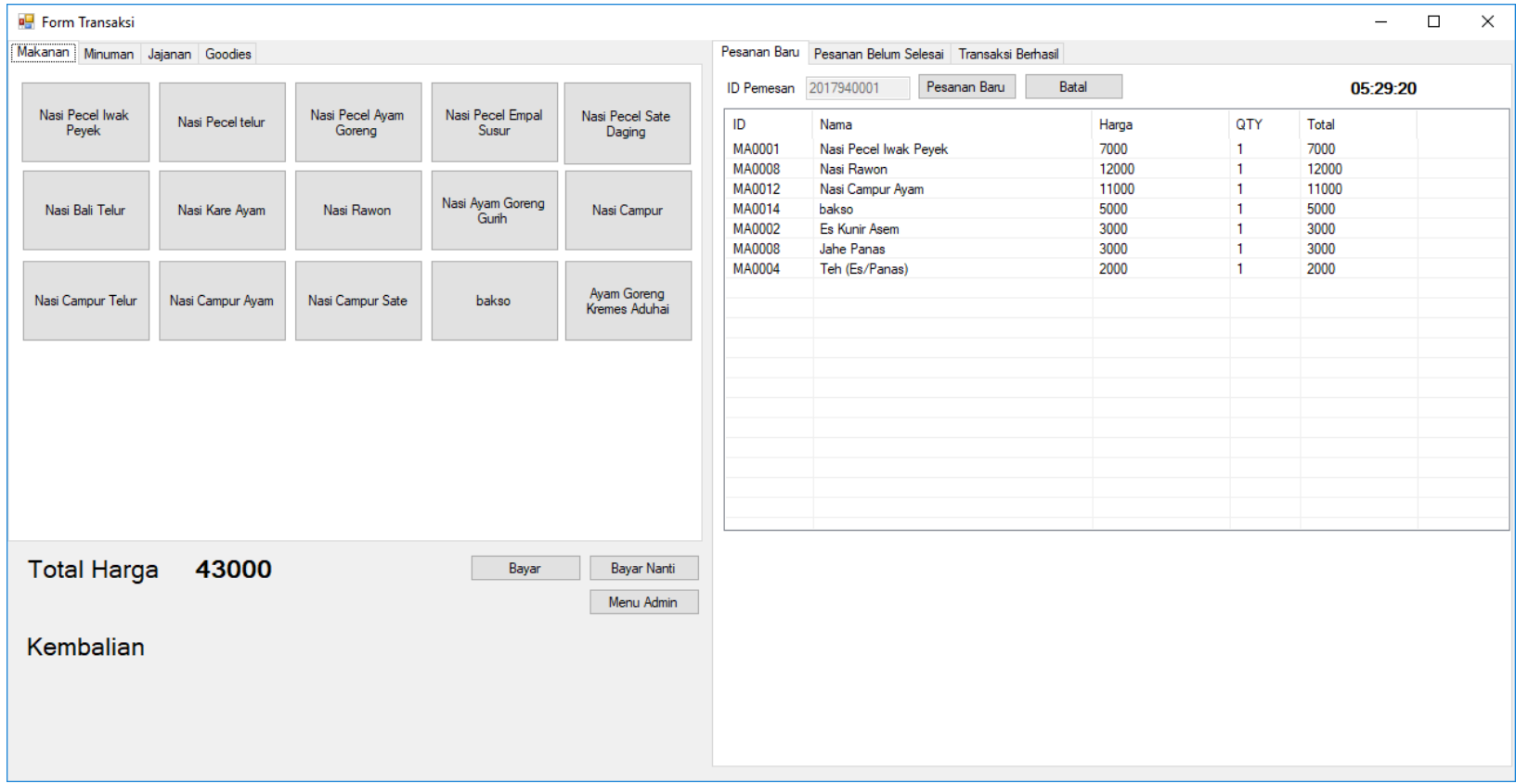

Gambar 4. Form Transaksi

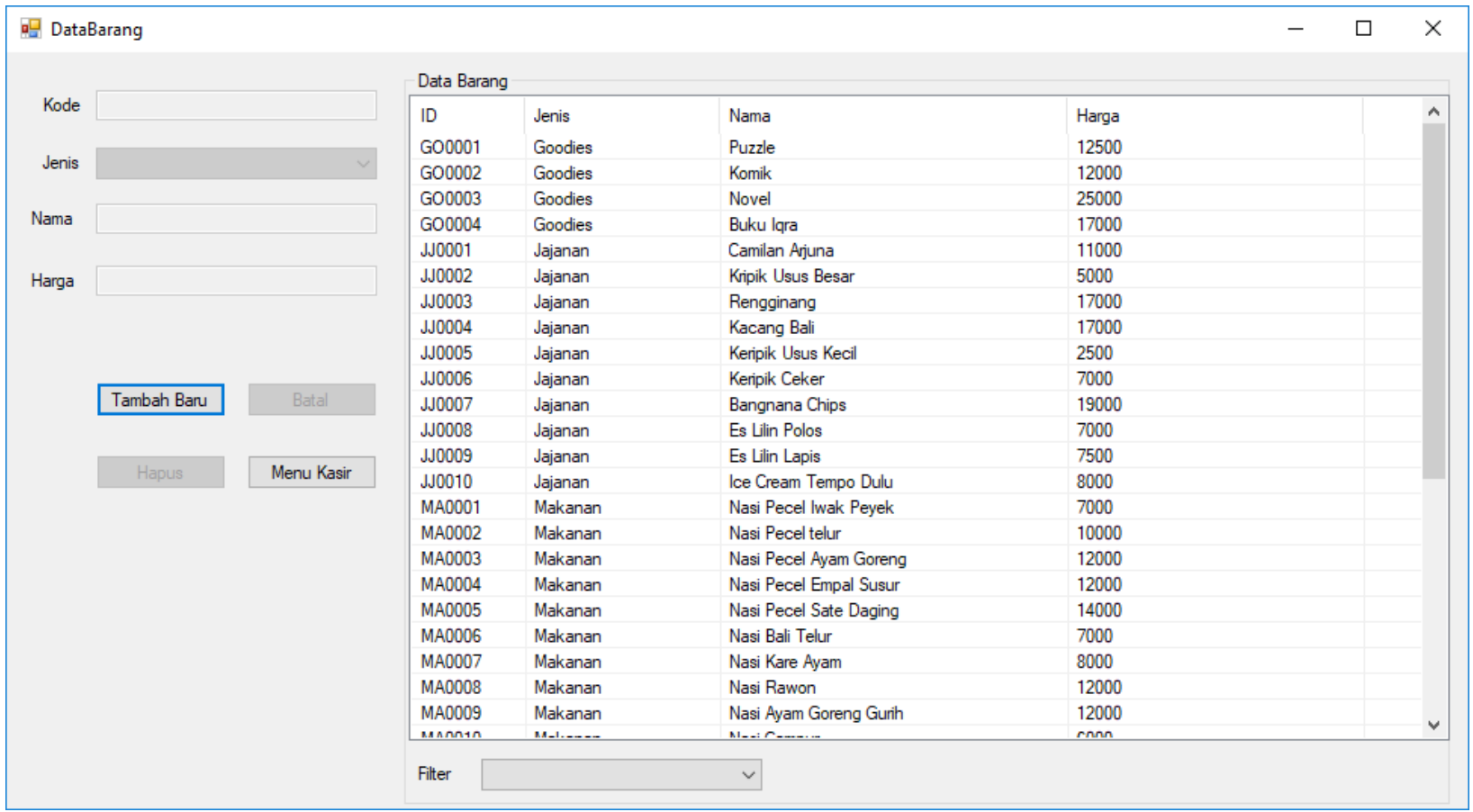

Gambar 5. Form Seting menu Admin 


\section{KESIMPULAN}

Dengan dibuatnya sistem informasi rumah makan pada warung nasional, maka pelanggan tingkat kepuasannya menjadi meningkat karena pelayanan pemesanan dan pembayaran di kasir menjadi lebih cepat sehingga antrian pelanggan dapat dihindarkan.

\section{DAFTAR PUSTAKA}

[1]. Akbar, M., Kodrat Iman Satoto, K.I., and Isnanto, R. (2014). Pembuatan Aplikasi Layanan Pesan Antar Makanan pada Sistem
Operasi Android. Jurnal TRANSMISI, Teknik Elektro, Universitas Diponegoro Semarang, Vol. 16, No. 04

[2]. Rachmawati, R. (2011). Peranan Bauran Pemasaran (Marketing Mix) terhadap Peningkatan Penjualan (Sebuah Kajian terhadap Bisnis Restoran). Jurnal Kompetensi Teknik Vol. 2, No. 02

[3]. Richard, C. and Robert, H. (2011). Modern Control Systems. Prentice Hall

[4]. Wijana, H.K. and Kurniawan, E. (2012). Sistem Informasi Manajemen Rumah Makan Berbasis Mobile, Jurnal EKSIS Vol 05 No 01 